\title{
Recognition of Similar appearing Gujarati Characters using Fuzzy-KNN Algorithm
}

\author{
Amit H. Choksi \\ Assistant Professor \\ Birla Vishvakarma Mahavidyalaya,V.V.Nagar, \\ Anand, Gujarat, India
}

\author{
Shital P. Thakkar \\ Assosiate Professor \\ Dharmsinh Desai University, \\ Nadiad, Gujarat, India
}

\begin{abstract}
This paper describes the Optical Character Recognition of similar appearing characters of Gujarati language. Gujarati language is a type of Indian language. Recognition accuracy of Gujarati Script is affected by characters very similar in shape. Here, Fuzzy KNN classifier in pair with two different features Geometric and Wavelet features are used to handle this problem. Fuzzy KNN not only label the class of pattern to be identified, it also decides strength of that pattern for that class. This makes use of Fuzzy KNN for imprecise class boundary. The test data for similar appearing characters are collected from various sources like scanned pages of text books of Gujarati language, newspapers etc. Train data set is prepared by typing Gujarati characters in different font types and size and then scanned.
\end{abstract}

\section{General Terms}

Optical Character Recognition, Fuzzy KNN, Wavelets.

\section{INTRODUCTION}

Gujarati is a major language of communication in the western subcontinent of India. Gujarati is deduced from Devnagri Script. Other variants derived from Devnagri Script are Sanskrit, Hindi and Marathi. Recognition of any Indian language is difficult compare to any European language because of its formation. All Indian Script are made of complex characters compared to Latin alphabets. In Indian Script basic characters can be vowel or consonant. Basic characters are also present with modifiers as shown in figure.1. This combination of core syllable with modifiers makes a large data set of characters to be identified.

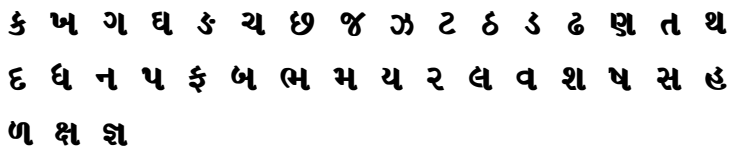

Fig 1: Gujarati script

Recognition of characters in any language is a problem of pattern recognition. Thus, Characters can be accurately classified if they are different by their structure. As shown in figure.1 some symbols like/cha /gha $\mathbf{g} /$ are very much similar by shape and structure. Often, these characters are misclassified even by humans who then need to use context knowledge to correct the error. Recognition of these characters requires proper feature extraction techniques and classification technique having sensitivity to small change in shape.

\section{PREVIOUS WORK}

Recognition of some other Indian scripts such as Tamil, Telugu and Bangla have been described in [19]. A feature based approach has been adopted by [24] for Telugu script recognition which works on isolated characters. All of these are limited to small subset of total number of symbols to be recognized. Work on analyzing Gujarati documents is started in 1999 by Antani and Agnihotri [10]. Their work was focused on classifying a subset of Gujarati characters. They used Euclidian Minimum Distance and K-Nearest Neighbor classifiers with feature extraction by regular and invariant moments. For that small set of similar appearing subset they achieved recognition rate of $67 \%$. After that Dholakia, Negi and Rama Mohan [9] applied techniques to identify three major zones of Gujarati Script: base symbol zone, upper modifier zone and lower modifier zone. After identification of zones each syllable and modifiers can be separately recognized. Yajnik and Rama Mohan [7],[11] performed recognition of Gujarati Numarals and characters by Wavelets and Neural Networks. Shah and Sharma [14] implemented OCR for Gujarati Script using Template Matching. They achieved low recognition accuracy. Finally, Dholakia, Negi and Yajnik [13] presented confusion character set or similar appearing characters. They used Wavelets for feature extraction and General Regression Neural Network as classifier. So far they have highest reported recognition accuracy of $97 \%$. They have given confusion set or misclassification of characters with other symbols having similar structure. They mentioned need of special methods to recognize these similar appearing symbols. In this paper, a try to resolve these confusions have been made with Fuzzy KNN classifier.

\section{GUJARATI SCRIPT}

Gujarati is a phonetic language spoken in western part of India. Gujarati has 11 vowels and $34+2 *$ consonants shown in figure.1. Vowels individually appear in Gujarati script or it is attached in the form of unique symbol with consonant called modifier or Matra. The matra can appear before, after, above or below of main consonant. Figure 1 shows core consonants, vowels and vowel modifiers of Gujarati script. Consonants can also appear in joint form of joint letters called conjuncts which is also good problem to deal for complete Gujarati Character Recognition System.

\section{GENERATION OF DATASET}

The data samples used in the experiment were obtained from various sites on the Internet and from scanned images of printed Gujarati text documents and newspapers. As a goal is 
to recognize similar appearing symbols have taken sample and test symbols of the characters shown in table 1 . The images in the database are from 15 font families with four font size as shown in results and observation part. The sample (training) data set consists of 18 characters (classes) each having 20 samples. The characters have been extracted from images of these fonts. The test set consists of 30 samples of each character with a variety of regular, bold and italic. The characters were manually cropped from the scanned (scanned at $300 \mathrm{dpi}$ ) images and resized to the selected size. Training data set is created by typing characters of all classes in different fonts and then scanning at $300 \mathrm{dpi}$. For test data set to create variety in the images, a method suggested in [23] was adopted. The images are scaled up and then scaled down to a fixed size. Due to the digitizing effect of scaling, the new scaled character would represent the real noise found in typical samples.

Table 1. Confusion matrix of similar appearing symbols

\begin{tabular}{|c|c|}
\hline Test Symbol & $\begin{array}{c}\text { Confusing } \\
\text { Symbol }\end{array}$ \\
\hline અ(a) & ચ(cha) \\
\hline$\varphi($ sha $)$ & $\mathrm{u}(\mathrm{pa})$ \\
\hline G(ba) & v(kha) \\
\hline d(ta) & $f(n a)$ \\
\hline$\gamma(\mathrm{ja})$ & $\gamma$ (four) \\
\hline$\xi(\mathrm{ka})$ & ₹(fa) \\
\hline ध(dha) & घ(gha) \\
\hline$\delta(i)$ & $\delta($ ee $)$ \\
\hline G(u) & З(оo) \\
\hline २(ra) & २(two) \\
\hline $\mathrm{u(pa)}$ & 4 (five) \\
\hline
\end{tabular}

Here it has not described the usual preprocessing phases that separate words from sentences and characters from words. It also does not have skew correction or noise removal etc. These are preprocessing phases in a typical text reading system as described in [22] which is not described here but implemented separately to understand steps for complete OCR. Table 2 shows the subset of characters selected for this experiment. The characters have the following phonetics, /ba/\&/kha/, $/ \mathrm{ka} / \& / \mathrm{fa} /, \quad / \mathrm{a} / \& / \mathrm{cha} /, \quad / \mathrm{i} / \& / \mathrm{ee} /, \quad / \mathrm{ra} / \& / \mathrm{two} /$, /pa/\&/five/, /sha/\&/pa/, /ta/\&/na/, /ja/\&/four/.

\section{FEATURES SELECTION}

Feature selection is one of the most important steps in developing a classification system because this would help classification systems to discriminate between samples specifically when symbols are very similar as shown in table 2. This section describes the various features selected for classification of the selected characters. Wavelets are very good in time and frequency localization, they are used by many researchers as feature extractor [11],[7]. Families of wavelet basis vectors by Ingrid Daubechies are very well localized in space as well as in frequency. In [12] authors have shown Daubechies D-4 wavelets give better results for handwritten Chinese character recognition than the other wavelets. It is also shown that D-4 gives better results than other statistical methods used for feature extraction. This experiment compared results of geometrical features with wavelet features. Here 46 structural and geometric features [6] like Number of horizontal lines, Number of vertical lines, Number of Right diagonal lines, Number of Left diagonal lines, Normalized Length of all horizontal lines, Normalized Length of all vertical lines, Normalized Length of all right diagonal lines, Normalized Length of all left diagonal lines, Normalized Area of Skeleton with three types of scaling have been used to perform this experiment.

\section{CLASSIFIERS}

Various classifiers have been studied for recognition of Indian Scripts [19],[8]. Classifiers with lowest complexity like Template Matching [14],[16],[17] to highest complexity like Neural Networks[7],[11] have been tested for recognition of Indian Scripts to achieve good recognition accuracy. Among all available classifier Fuzzy KNN has been selected for similar appearing symbols.

\subsection{K-Nearest Neighbour}

In KNN algorithm [1],[2] Euclidean distance between Test samples and correctly identified samples set is measured. Label to test sample is given a class based on K-closest Neighbours. Euclidean distance between two samples $\mathrm{a}_{1=}\left(\mathrm{a}_{1,1}, \ldots \ldots \ldots \mathrm{a}_{1, \mathrm{k}}\right) \quad$ and $\quad \mathrm{a}_{2=}\left(\mathrm{a}_{2,1}, \ldots \ldots \ldots \mathrm{a}_{2, \mathrm{k}}\right) \quad$ is. $d\left(a_{1}, a_{2}\right)={\sqrt{\sum_{j=1}^{k}\left(a_{1, j}-a_{2, j}\right)}}^{2}$

This algorithm is simple in computation and works well even in small sample size.

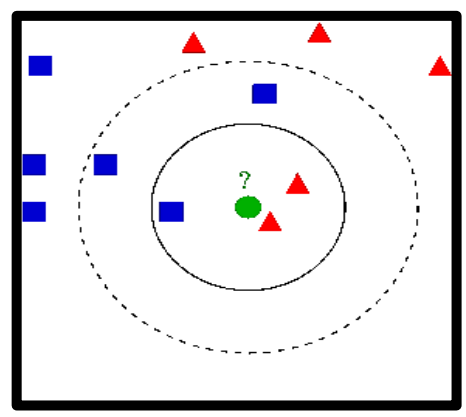

Fig 2: Example of KNN

As shown in figure 2 [5], the test sample is circle. First class is squares and second class is of triangles. If closest neighbours considered are three $(K=3)$ then circle is classified to class of triangle. If $K=5$ then it is classified to square. KNN has advantages of being Nonparametric and works well on small sample size. There are three limitations [1],[2],[15] of $\mathrm{KNN}: 1$ ) when $\mathrm{K}$ is greater than one and if numbers of train samples of different classes are same than there will tie for assignment of a specific class. 2) When any input vector (test sample) is assigned to class, it does not indicate intensity of vector to that class. 3) All class is considered with equal strength in assignment of the class label to test sample.

\subsection{Fuzzy KNN}

To avoid above mentioned disadvantages of KNN algorithm fuzzy set concept is introduced into it [15]. Fuzzy set was used by Zadeh in 1965 [3]. A "Fuzzy KNN" algorithm utilizes strength of test sample into any class called fuzzy class membership and thus produces fuzzy classification rule [15]. An example of Fuzzy set is the set of real numbers much larger than zero, which can be defined with a membership function as follows: 
$\mathrm{u}(\mathrm{x})=\left\{\begin{array}{l}x^{2} /\left(x^{2}+1\right), x \geq 0 \\ 0, x<0\end{array}\right.$

Numbers less than zero are not in the set because value of membership function for those is zero. While numbers larger than zero are in the set based on strength of numbers with respect to zero. This makes Fuzzy Set a useful tool for classification of samples having imprecise boundary. Fuzzy Set gives degree of presence of any sample into specific class. As mentioned in [15], use of Fuzzy Set in KNN improves its classification results for pattern recognition. Thus, Fuzzy KNN can be a useful algorithm to deal classification of similar appearing symbols mentioned in table 1. Suppose, input sample set is $\left\{x_{1}, \ldots \ldots \ldots \ldots, x_{n}\right\}$ is to partitioned into $C$ classes. Then it is required to find fuzzy membership value of each input vector into $C$ classes given by $u_{i k}=u_{i}\left(x_{k}\right)$ for $i=$ $1, \ldots \ldots, C$ and $k=1, \ldots \ldots, n$. Here $u_{i k}$ is the degree of membership of kth sample into classes $i$. It is denoted by the $C$ by $n$ matrix on $\mathrm{U}$. The following properties must be true for $U$ to be a fuzzy $C$ partition.

$$
\begin{aligned}
& \sum_{i=1}^{c} \boldsymbol{u}_{i k}=1 \\
& \mathrm{O}<\sum_{i=1}^{m} \boldsymbol{u}_{i k}<n \\
& \boldsymbol{u}_{i k} \in[0,1]
\end{aligned}
$$

The Fuzzy K-Nearest Neighbour algorithm assigns class membership to a test sample rather than defining specific class. For example, an input character sample is assigned a membership of 0.8 to one class and 0.2 to other class than that sample belongs to class one than the other. But if a vector is assigned membership value of 0.55 to one class and 0.45 to other class than input vector must be examined further for assignment of a class. $u_{\mathrm{i}}(\mathrm{x})$ can be found [15] by

$$
u_{i}(x)=\frac{\sum_{j=1}^{K} u_{i j}\left(1 /\left\|x-x_{j}\right\|^{2 /(m-1)}\right)}{\sum_{j=1}^{K}\left(1 /\left\|x-x_{j}\right\|^{2 /(m-1)}\right)}
$$

As shown in equation (4) membership value depends on the inverse of the distances from the nearest neighbours and their class membership. Because of inverse distance input sample's membership is more if it is near and less if it is farther from the sample vector into consideration. In equation the variable $m$ determines how heavily the distance is weighted when calculating each neighbour's contribution to the membership value. If $m$ is two, then contribution of each neighbouring point is weighted by reciprocal of its distance from the point being classified. As $m$ increases, the neighbours are more evenly weighted, and their relatives' distances from the point being classified have less effect. As $m$ approaches one, the closer neighbours are weighted far more heavily than those farther away, which have the effect of reducing the number of points that contribute to the membership value of point being classified.

\section{RESULTS AND OBSERVATION}

\subsection{Test set-1}

Table 2 shows results of db1 wavelet features with FKNN

\begin{tabular}{|c|c|c|c|c|c|}
\hline \multirow[t]{2}{*}{$\begin{array}{c}\text { Confusion } \\
\text { Symbols }\end{array}$} & \multirow[t]{2}{*}{$\begin{array}{c}\text { Font } \\
\text { Size }\end{array}$} & \multirow[t]{2}{*}{ Data } & \multirow[t]{2}{*}{$\begin{array}{l}\text { Test } \\
\text { Data }\end{array}$} & $\begin{array}{c}\text { Detail } \\
\text { Coefficients } \\
\text { 64 Features }\end{array}$ & $\begin{array}{c}\text { Approximation } \\
\text { Coefficients } 64 \\
\text { features }\end{array}$ \\
\hline & & & & $\begin{array}{c}\mathrm{ACC} \\
(\%)\end{array}$ & $\begin{array}{c}\mathrm{ACC} \\
(\%)\end{array}$ \\
\hline \multirow{4}{*}{$\begin{array}{c}\text { અ(a) } \\
\text { ચ(cha) }\end{array}$} & 15 & \multirow{4}{*}{40} & \multirow{4}{*}{30} & 90 & 100 \\
\hline & 17 & & & 96.67 & 100 \\
\hline & 19 & & & 100 & 100 \\
\hline & 20 & & & 100 & 100 \\
\hline \multirow{4}{*}{$\begin{array}{l}r(\mathrm{ta}) \\
ન(\mathrm{na})\end{array}$} & 15 & \multirow{4}{*}{40} & \multirow{4}{*}{30} & 53.33 & 100 \\
\hline & 17 & & & 83.34 & 100 \\
\hline & 19 & & & 70 & 100 \\
\hline & 20 & & & 86.67 & 100 \\
\hline \multirow{4}{*}{$\begin{array}{l}\gamma(\text { four }) \\
\gamma(\mathrm{ja})\end{array}$} & 15 & \multirow{4}{*}{40} & \multirow{4}{*}{30} & 93.34 & 100 \\
\hline & 17 & & & 100 & 100 \\
\hline & 19 & & & 96.67 & 100 \\
\hline & 20 & & & 100 & 100 \\
\hline \multirow{4}{*}{$\begin{array}{l}\text { બ(ba) } \\
\text { ધ(kha) }\end{array}$} & 15 & \multirow{4}{*}{40} & \multirow{4}{*}{30} & 80 & 100 \\
\hline & 17 & & & 80 & 100 \\
\hline & 19 & & & 100 & 100 \\
\hline & 20 & & & 100 & 100 \\
\hline \multirow{4}{*}{$\begin{array}{l}\text { ฯ(sha) } \\
\text { ч(pa) }\end{array}$} & 15 & \multirow{4}{*}{40} & \multirow{4}{*}{30} & 86.67 & 100 \\
\hline & 17 & & & 80 & 96.67 \\
\hline & 19 & & & 73.34 & 96.67 \\
\hline & 20 & & & 100 & 100 \\
\hline \multirow{4}{*}{$\begin{array}{l}\text { ઘ(dha) } \\
\text { ઘ(gha) }\end{array}$} & 15 & \multirow{4}{*}{40} & \multirow{4}{*}{30} & 60 & 90 \\
\hline & 17 & & & 90 & 96.67 \\
\hline & 19 & & & 96.67 & 100 \\
\hline & 20 & & & 100 & 100 \\
\hline \multirow{4}{*}{$\begin{array}{c}\xi(i) \\
\xi(\text { ee })\end{array}$} & 15 & \multirow{4}{*}{40} & \multirow{4}{*}{30} & 100 & 100 \\
\hline & 17 & & & 100 & 100 \\
\hline & 19 & & & 100 & 100 \\
\hline & 20 & & & 100 & 100 \\
\hline \multirow{4}{*}{$\begin{array}{c}3(\mathrm{u}) \\
\text { З(oo) }\end{array}$} & 15 & \multirow{4}{*}{40} & & 100 & 100 \\
\hline & 17 & & 30 & 100 & 100 \\
\hline & 19 & & & 100 & 100 \\
\hline & 20 & & & 100 & 100 \\
\hline & 15 & & & 100 & 100 \\
\hline$\xi(\mathrm{ka})$ & 17 & 40 & 30 & 96.67 & 100 \\
\hline$\xi(f a)$ & 19 & & & 100 & 100 \\
\hline & 20 & & & 100 & 100 \\
\hline
\end{tabular}
classifier.
Table 2. FKNN using (db1) wavelet features for similar appearing symbols

As the wavelets are known for their shape invariant nature works well for feature extraction. Here db1 wavelet at level 2 has been used, so the character of $32 X 32$ is scaled to $8 X 8$, hence obtained total 64 features. As discussed earlier train samples are 40 (20 of each confusing member) were taken printing and scanning characters from different font families and 30 test samples from news papers and other scanned document. Here in table 2 recognition results by 64 detailed (high-high) and approximate (low-low) coefficients are also compared. As detailed coefficients contain high frequency details not good as classifier compare to approximation coefficients. 


\subsection{Test set-2}

Results in table 3 are with 46 geometric and structural features and FKNN classifier. Geometric and structural feature are based on shape, structure and geometry of characters.

Table 3. FKNN using 46 geometrical features for similar appearing symbols

\begin{tabular}{|c|c|c|c|c|c|c|}
\hline \multirow{2}{*}{$\begin{array}{c}\text { Confusion } \\
\text { Symbols }\end{array}$} & \multirow{2}{*}{$\begin{array}{c}\text { Font } \\
\text { Size }\end{array}$} & \multirow[t]{2}{*}{ Data } & \multirow{2}{*}{$\begin{array}{l}\text { Test } \\
\text { Data }\end{array}$} & $17 \times 17$ & $19 \times 19$ & $21 \times 21$ \\
\hline & & & & $\begin{array}{c}\text { ACC } \\
(\%)\end{array}$ & $\begin{array}{l}\mathrm{ACC} \\
(\%)\end{array}$ & $\begin{array}{l}\mathrm{ACC} \\
(\%)\end{array}$ \\
\hline \multirow{4}{*}{$\begin{array}{c}\text { અ(a) } \\
\text { ચ(cha) }\end{array}$} & 15 & \multirow{4}{*}{40} & \multirow{4}{*}{30} & 80 & 86.67 & 86.67 \\
\hline & 17 & & & 76.67 & 80 & 60 \\
\hline & 19 & & & 83.34 & 73.34 & 80 \\
\hline & 20 & & & 73.34 & 66.67 & 63.34 \\
\hline \multirow{4}{*}{$\begin{array}{l}t(\mathrm{ta}) \\
ન(\mathrm{na})\end{array}$} & 15 & \multirow{4}{*}{40} & \multirow{4}{*}{30} & 60 & 50 & 50 \\
\hline & 17 & & & 66.67 & 60 & 66.67 \\
\hline & 19 & & & 73.34 & 66.67 & 56.67 \\
\hline & 20 & & & 80 & 76.67 & 80 \\
\hline \multirow{4}{*}{$\begin{array}{c}\gamma \text { (four) } \\
\gamma(\mathrm{ja})\end{array}$} & 15 & \multirow{4}{*}{40} & \multirow{4}{*}{30} & 73.34 & 100 & 73.34 \\
\hline & 17 & & & 100 & 96.67 & 100 \\
\hline & 19 & & & 100 & 90 & 90 \\
\hline & 20 & & & 66.67 & 66.67 & 60 \\
\hline \multirow{4}{*}{$\begin{array}{c}\text { બ(ba) } \\
\text { બ(kha) }\end{array}$} & 15 & \multirow{4}{*}{40} & \multirow{4}{*}{30} & 60 & 63.34 & 63.34 \\
\hline & 17 & & & 66.67 & 60 & 60 \\
\hline & 19 & & & 73.34 & 93.34 & 66.67 \\
\hline & 20 & & & 80 & 100 & 100 \\
\hline \multirow{4}{*}{$\begin{array}{l}\Psi(\text { sha }) \\
\mathrm{u}(\mathrm{pa})\end{array}$} & 15 & \multirow{4}{*}{40} & \multirow{4}{*}{30} & 66.67 & 66.67 & 80 \\
\hline & 17 & & & 66.67 & 73.34 & 66.67 \\
\hline & 19 & & & 60 & 70 & 60 \\
\hline & 20 & & & 80 & 73.34 & 83.34 \\
\hline \multirow{4}{*}{$\begin{array}{l}\text { ઘ(dha) } \\
\text { ઘ(gha) }\end{array}$} & 15 & \multirow{4}{*}{40} & \multirow{4}{*}{30} & 60 & 60 & 60 \\
\hline & 17 & & & 83.34 & 73.34 & 66.67 \\
\hline & 19 & & & 83.34 & 70 & 86.67 \\
\hline & 20 & & & 60 & 80 & 73.34 \\
\hline \multirow{4}{*}{$\begin{array}{c}\delta(\mathrm{i}) \\
\delta(\mathrm{ee})\end{array}$} & 15 & \multirow{4}{*}{40} & \multirow{4}{*}{30} & 86.67 & 100 & 76.67 \\
\hline & 17 & & & 66.67 & 66.67 & 66.67 \\
\hline & 19 & & & 60 & 80 & 66.67 \\
\hline & 20 & & & 73.34 & 86.67 & 70 \\
\hline \multirow{4}{*}{$\begin{array}{l}\text { G(u) } \\
\text { औ(oo) }\end{array}$} & 15 & \multirow{4}{*}{40} & & 73.34 & 86.67 & 80 \\
\hline & 17 & & 30 & 66.67 & 66.67 & 73.34 \\
\hline & 19 & & & 80 & 80 & 76.67 \\
\hline & 20 & & & 83.34 & 83.34 & 83.34 \\
\hline & 15 & & & 80 & 83.34 & 76.67 \\
\hline$\xi(\mathrm{ka})$ & 17 & 40 & 30 & 100 & 90 & 93.34 \\
\hline$\xi(\mathrm{fa})$ & 19 & & & 96.67 & 83.34 & 96.67 \\
\hline & 20 & & & 86.67 & 93.34 & 83.34 \\
\hline
\end{tabular}

From table 3 it is observed that for the pair $\xi \boldsymbol{\&} \xi$, achieved efficiency is $100 \%$ with scaling of $17 X 17$, but for pair $\delta \& \delta$, achieved efficiency is $100 \%$ with scaling of $19 \times 19$. Here it is also observed that character size from the scanned document is changed than size of character in the dataset because of scanning, so the test symbols has been scaled to three scaling size as mention above. Variation in above results and efficiency is due to the digitizing effect of scaling as the new scaled character would represent the noise in the test samples.
Also it has been found that these features do not contain complete detail of character based on shape and geometry. Because of this in some confusion pair results are good, but average for other pairs.

\subsection{Test set-3}

Here in table 4, the FKNN is tested on confusion pairs from the scanned newspapers in which type of font or font size is unknown. In this experiment the deformation is also created manually by changing the height and width of the character. Some of test images are first scaled up and then scaled down to a fixed size hence obtained the deformated character. Here FKNN classifier also has been checked for its working on symbols from unknown source or not. From table 4, it can be said that for 8 confusion pair obtained efficiency is $95 \%$, but for the confusion pair $\boldsymbol{\varepsilon} \& \boldsymbol{\varepsilon}$ efficiency is $62.50 \%$. This less accuracy is observed because of scaling. After scaling both letters are differing by only few pixels means almost same.

Table 4. Testing of similar appearing symbols from scanned newspapers with (db4) wavelet features

\begin{tabular}{|c|c|c|c|}
\hline $\begin{array}{c}\text { Confusion } \\
\text { Symbols }\end{array}$ & Test Data & Hits & $\begin{array}{c}\mathrm{ACC} \\
(\%)\end{array}$ \\
\hline $\begin{array}{c}\text { અ(a) } \\
\text { ચ(cha) }\end{array}$ & 40 & 40 & 100 \\
\hline $\begin{array}{l}\text { ત(ta) } \\
\text { t(na) }\end{array}$ & 40 & 36 & 90 \\
\hline $\begin{array}{c}\gamma \text { (four) } \\
\gamma(\mathrm{ja})\end{array}$ & 40 & 38 & 95 \\
\hline $\begin{array}{l}\text { બ(ba) } \\
\text { ㅂ(kha) }\end{array}$ & 40 & 34 & 85 \\
\hline $\begin{array}{l}\mathrm{Y}(\mathrm{sha}) \\
\mathrm{u}(\mathrm{pa})\end{array}$ & 40 & 31 & 77.50 \\
\hline $\begin{array}{l}\text { ध(dha) } \\
\text { ઘ(gha) }\end{array}$ & 40 & 25 & 62.50 \\
\hline $\begin{array}{c}\delta(\mathrm{i}) \\
\delta(\mathrm{ee})\end{array}$ & 40 & 38 & 95 \\
\hline $\begin{array}{c}3(\mathrm{u}) \\
3(\mathrm{oo})\end{array}$ & 40 & 38 & 95 \\
\hline $\begin{array}{l}\xi(\mathrm{ka}) \\
\xi(\mathrm{fa})\end{array}$ & 40 & 34 & 85 \\
\hline
\end{tabular}

\subsection{Test set-4}

In table 5 we compared between $\mathrm{db} 1$ and $\mathrm{db} 4$ wavelet approximation coefficients. The results after using the wavelet $\mathrm{db} 1$ and $\mathrm{db} 4$ are almost same. Only in three confusion pairs there is a minor change of efficiency. So any wavelet among $\mathrm{db} 1$ and $\mathrm{db} 4 \mathrm{can}$ be used for this application. 
Table 5. Comparision of $\mathrm{db} 1$ and $\mathrm{db} 4$ wavelets for similar appearing symbols

\begin{tabular}{|c|c|c|c|c|c|}
\hline \multirow[t]{2}{*}{$\begin{array}{c}\text { Confusion } \\
\text { Symbols }\end{array}$} & \multirow[t]{2}{*}{$\begin{array}{l}\text { Font } \\
\text { Size }\end{array}$} & \multirow[t]{2}{*}{ Data } & \multirow[t]{2}{*}{$\begin{array}{l}\text { Test } \\
\text { Data }\end{array}$} & $\begin{array}{l}\text { db1 Wavelet } \\
64 \text { Features }\end{array}$ & $\begin{array}{l}\text { db4 Wavelet } \\
64 \text { features }\end{array}$ \\
\hline & & & & $\begin{array}{c}\text { ACC } \\
(\%)\end{array}$ & $\begin{array}{c}\mathrm{ACC} \\
(\%)\end{array}$ \\
\hline \multirow{4}{*}{$\begin{array}{c}\text { અ(a) } \\
\text { ચ(cha) }\end{array}$} & 15 & \multirow{4}{*}{40} & \multirow{4}{*}{30} & 100 & 100 \\
\hline & 17 & & & 100 & 100 \\
\hline & 19 & & & 100 & 100 \\
\hline & 20 & & & 100 & 100 \\
\hline \multirow{4}{*}{$\begin{array}{l}\lambda(\text { ta) } \\
ન(n a)\end{array}$} & 15 & \multirow{4}{*}{40} & \multirow{4}{*}{30} & 100 & 100 \\
\hline & 17 & & & 100 & 100 \\
\hline & 19 & & & 100 & 96.67 \\
\hline & 20 & & & 100 & 100 \\
\hline \multirow{4}{*}{$\begin{array}{c}\gamma(\text { four }) \\
\gamma(\mathrm{ja})\end{array}$} & 15 & \multirow{4}{*}{40} & \multirow{4}{*}{30} & 100 & 100 \\
\hline & 17 & & & 100 & 100 \\
\hline & 19 & & & 100 & 100 \\
\hline & 20 & & & 100 & 100 \\
\hline \multirow{4}{*}{$\begin{array}{c}\text { બ(ba) } \\
\text { ખ(kha) }\end{array}$} & 15 & \multirow{4}{*}{40} & \multirow{4}{*}{30} & 100 & 100 \\
\hline & 17 & & & 100 & 100 \\
\hline & 19 & & & 100 & 100 \\
\hline & 20 & & & 100 & 100 \\
\hline \multirow{4}{*}{$\begin{array}{l}\text { ४(sha) } \\
\text { ч(pa) }\end{array}$} & 15 & \multirow{4}{*}{40} & \multirow{4}{*}{30} & 100 & 100 \\
\hline & 17 & & & 96.67 & 100 \\
\hline & 19 & & & 96.67 & 96.67 \\
\hline & 20 & & & 100 & 100 \\
\hline \multirow{4}{*}{$\begin{array}{l}\text { ઘ(dha) } \\
\text { ઘ(gha) }\end{array}$} & 15 & \multirow{4}{*}{40} & \multirow{4}{*}{30} & 90 & 100 \\
\hline & 17 & & & 96.67 & 96.67 \\
\hline & 19 & & & 100 & 93.34 \\
\hline & 20 & & & 100 & 100 \\
\hline \multirow{4}{*}{$\begin{array}{l}\delta(\mathrm{i}) \\
\delta(\mathrm{ee})\end{array}$} & 15 & \multirow{4}{*}{40} & \multirow{4}{*}{30} & 100 & 100 \\
\hline & 17 & & & 100 & 100 \\
\hline & 19 & & & 100 & 100 \\
\hline & 20 & & & 100 & 100 \\
\hline \multirow{4}{*}{$\begin{array}{c}G(\mathrm{u}) \\
\text { औ(oo) }\end{array}$} & 15 & \multirow{4}{*}{40} & & 100 & 100 \\
\hline & 17 & & 30 & 100 & 100 \\
\hline & 19 & & & 100 & 100 \\
\hline & 20 & & & 100 & 100 \\
\hline f(ka) & 15 & & & 100 & 100 \\
\hline & 17 & 40 & 30 & 100 & 100 \\
\hline & 19 & & & 100 & 100 \\
\hline & 20 & & & 100 & 100 \\
\hline
\end{tabular}

Table 6. Comparative Results for similar appearing Symbols

\begin{tabular}{|c|c|c|}
\hline Sr. No. & Classifier & $\begin{array}{c}\text { Recognition } \\
\text { Accuracy }\end{array}$ \\
\hline 1 & K- Nearest Neighbour & $67 \%$ \\
\hline 2 & $\begin{array}{c}\text { General Regression } \\
\text { Neural Network }\end{array}$ & $97 \% *$ \\
\hline 3 & Fuzzy KNN & $100 \%$ \\
\hline
\end{tabular}

*Here this recognition accuracy claimed is for all Gujarati characters.

\section{CONCLUSION}

The purpose of this experiment is to implement recognition of similar appearing symbols Gujarati text. To observe behavior of algorithm for real time print problems, various deformations have been created like change in the height, width and size of character, scaled up and then scale down to fix size. The problem of similar appearing symbols is solved using FKNN classifier with Structural and Wavelet features. FKNN classifier gives good results as it considers membership value of characters similar in nature into their respective class. Results of Wavelet features are best compared to Structural features as shape of character was affected by scaling. Result of Wavelet features are almost $100 \%$. Recognition accuracy obtained for similar appearing characters with KNN [10] were only $67 \%$. Recognition accuracy claimed by GRNN classifier is highest so far but it is for all Gujarati characters. Overall recognition was affected there by similar characters. Less recognition efficiency were observed in printed and scanned Gujarati newspapers because of broken characters and insufficient print quality.

\section{ACKNOWLEDGMENTS}

Special thanks to Dr. H.S.Mazumdar, Head of R \& D Department, Dharmsinh Desai University, for his guidance.

\section{REFERENCES}

[1] R.O. Duda and P.E. Hart, Pattern Classification and scene Analysis. New York : Wiley,1973.

[2] T.M.Cover and P.E.Hart,“ Nearest Neighbour pattern classification," IEEE Trans. Inform. Theory, vol.17,no.1, pp. 15-28,1978.

[3] L.A.Zadeh, " Fuzzy Sets," Inf. Control, vol.8, pp. 338353,1965 .

[4] R C Gonzalez and R E Woods. "Digital Image Processing". Publication Addison-Wesley, 1993.

[5] http://en.wikipedia.org/wiki/KNN algorithm.

[6] Dinesh Dilip, "A Feature Extraction Technique Based on Character Geometry for Character Recognition", Department of Electronics and Communication Engineering, Amrita School of Engineering, Kollam, Kerala.

[7] A. Yajnik, S. Rama Mohan, "Identification of Gujarati Characters Using Wavelets and Neural Network", Proc.Of 10th IASTED International Conference on Artificial Intelligence and Soft Computing, Acta press, 2006, pp. 150-155.

[8] Atul Negi, Chakravarthy Bhagvati, and B. Krishna. "An OCR System for Telugu". Proc. of 6th ICDAR, IEEE Computer Society, 2001, pp. 1110-1114.

[9] Jignesh Dholakia, Atul Negi, S. Rama Mohan, "Zone Identification in the Printed Gujarati Text", Proc. of $8^{\text {th }}$ ICDAR, IEEE Computer Society, 2005, pp. 272-276.

[10] Sameer Antani, Lalitha Agnihotri, "Gujarati Character Recognition”, Proc. 5th ICDAR, IEEE Computer Society, 1999, pp. 418-422.

[11] S. Rama mohan, A. Yajnik, "Gujarati Numeral Recognition Using Wavelets and Neural Network", Proc. Of 2ndIICAI, Pune, 2005, pp. 397-406.

[12] Lie Huang, Xiao Huang, "Multiresolution Recognition Of Offline Handwritten Chinese Characters With Wavelet Transform”, Proc. 6th ICDAR, IEEE Computer Society, 2001, pp. 631-634.

[13] Atul Negi, Jignesh Dholakia, A. Yajnik, "Wavelet Feature Based Confusion Character Sets for Gujarati 
Script" International Conference on Computational Intelligence and Multimedia Applications, 2007.

[14] "Design and Implementation of Optical Character Recognition System to Recognize Gujarati Script using Template Matching”' by Prof S K Shah, A Sharma.

[15] J. M. Keller, M. R. Gray, and J. A. Givens, Jr., "A Fuzzy K-Nearest Neighbor Algorithm", IEEE Transactions on Systems, Man, and Cybernetics, Vol. 15, No. 4, pp. 580585 .

[16] O D Trier, A K Jain and T Taxt. 'Feature Extraction Methods for Character Recognition - A Survey'. Pattern Recognition, vol 29, no 4, 1996,pp 641-662.

[17] D M Gavrila, D Benze. 'Multi Feature Hierarchical Template Matching using Distance Transforms'. Proceedings of ICDAR, 2001

[18] A. Hashizume, P. S. Yeh, A. Rosenfeld, "A method of detecting the orientation of aligned components", Pattern Recognition Letters, 1996, pp. 125-132.

[19] B. V. Dasarathy. Nearest neighbor (NN) norms, NN pattern classification techniques. 1991.
[20] U Pal, B B Choudhuri: Indian Script Character Recognition: A Survey of Pattern Recognition, Vol. 37,pp. 1887-1899, 2004.

[21] N. Sharma, U. Pal, and F. Kimura, "Recognition of Handwritten Kannada Numerals", Proc, of IEEE-ICIT 2006.

[22] W. K. Pratt. Digital Image Processing. Wiley Interscience, 1991.

[23] S. Tsujimoto and H. Asada. Major component of a complete text reading system. In L. O'Gorman and R. Kasturi, editors, Document Image Analysis, pages 298314, 1995.

[24] H. S. Baird. Document Image Defect Models. In L. O'Gorman and R. Kasturi, editors, Document Image Analysis, pages 315-325, 1995.

[25] Arun K. Pujari, C. Dhananjay Naidu, M. Sreenivasa Rao, B. C. Jingara, "An Adaptive Character Recognizer for Telugu Scripts using Multiresolution Analysis and Associative Memory", Image Vision Computing 22(14), 2004 , pp. 1221-1227. 